\title{
MIS416 as a siRNA Delivery System with the Ability to Target Antigen-Presenting Cells
}

\author{
Francesco Mainini,, David S. Larsen, ${ }^{2}$ Gill A. Webster, ${ }^{3}$ Sarah L. Young, ${ }^{1,4}$ and Michael R. Eccles ${ }^{1,4}$
}

MIS416 is a microparticulate formulation derived from propionibacterium acnes cell wall skeletons with intrinsic adjuvant activity. Conjugates of MIS416-SS-peptide containing a disulfide linkage facilitate the cytoplasmic delivery and release of peptides in antigen-presenting cells (APCs). We hypothesized that MIS416siRNA (small interfering RNA) conjugates, containing a disulfide linkage between MIS416 and the siRNA, would allow cytoplasmic release of siRNA in APCs. MIS416-SS-siStat3 conjugates added to cell culture medium of monolayers of DCs in culture flasks successfully targeted Stat3 mRNA in DCs in vitro without transfection, downregulating Stat3 mRNA and protein levels. These results suggest that MIS416-SS-siRNA conjugates can be used as a novel siRNA delivery system for the knockdown of mRNA levels in APCs.

Keywords: dendritic cells, Stat3, siRNA, gene silencing, delivery

\section{Introduction}

$\mathbf{R}$ ECENTLY, SMALL INTERFERING RNAs (siRNAs) have emerged as innovative nucleic acid-based therapies and candidates for the treatment of many diseases [1-4]. However, in vivo delivery of siRNA presents many challenges [5]. First, unmodified siRNAs are not stable in serum since they are easily degraded by RNAses, and in addition siRNAs are removed by renal clearance, resulting in a short half-life in blood [6]. Second, siRNAs are impermeable to cells, and a delivery system is required for delivery of siRNAs into the cytoplasm of target cells [7]. Third, siRNAs delivered to cells may become trapped in endosomes, leading to ineffective treatment due to degradation caused by specific DNAses and RNAses [8,9]. To overcome these barriers, siRNA delivery systems need to be designed with the ability to transport and deliver genetic material safely and efficiently. It is also potentially desirable that the delivery vector is able to target specific cells or cell types, with low cytotoxicity.

MIS416 is a bacterial cell wall skeleton derived from Propionibacterium acnes comprising multiple nucleotide-binding oligomerization domain-containing 2 (NOD-2) and toll-like receptor 9 (TLR-9) ligands that targets cytosolic receptors expressed by antigen-presenting cells (APCs) [10]. The manufacturing process generates a microparticulate suspension $(0.5 \times 2.0 \mu \mathrm{m}$ rods $)$ of minimal cell wall skeleton with bacterial DNA contained within the cage structure. This new delivery platform exploits phagocytic uptake mechanisms to achieve targeted delivery to both myeloid and plasmacytoid
DCs and other APCs [10]. Furthermore, the activation of NOD-2 and TLR-9 on APCs results in the upregulation of costimulatory molecules, such as major histocompatibility complex (MHC) I and II, CD86, and CD80 in DCs leading to an effective adaptive immune response in the host [11-13]. The potential use of MIS416 as a therapeutic cancer vaccine adjuvant was recently investigated in a melanoma cancer model [10] and in an epithelial ovarian cancer model [14] in association with $\mathrm{CD} 11 \mathrm{~b}$ therapy to remove myeloid-derived suppressive cells in the tumor microenvironment. The results showed that MIS416 treatment could delay tumor growth in both murine cancer models, and that MIS416 could synergize with other standard anticancer therapies, such as radiotherapy and with other more novel immunotherapy regimens [14].

We previously developed a conjugation strategy for the coupling of biotinylated peptides and other molecules to MIS416 using a streptavidin bridge [15]. This coupling methodology enabled attachment of fluorophores and peptides to investigate whether the inclusion of a disulfide bond in the linker could facilitate the release of the attached molecular cargos from MIS416. The results showed that inclusion of a disulfide bond in MIS416-SS-peptide conjugates induced more efficient release of peptides in the cytoplasm of DCs, an important consideration for MIS416-mediated delivery of degradation-sensitive cargos such as siRNAs.

Recently, Pradhan et al., reported a nucleic acid therapeutic strategy, involving targeting of dendritic cells (DCs) to influence DC function [16]. In their approach, therapeutic

Departments of ${ }^{1}$ Pathology, ${ }^{2}$ Chemistry, University of Otago, Dunedin, New Zealand.

${ }^{3}$ Innate Immunotherapeutics Ltd., Penrose, New Zealand.

${ }^{4}$ Maurice Wilkins Center for Molecular Biodiscovery, Auckland, New Zealand.

(c) Francesco Mainini et al. 2018; Published by Mary Ann Liebert, Inc. This Open Access article is distributed under the terms of the Creative Commons License (http://creativecommons.org/licenses/by/4.0), which permits unrestricted use, distribution, and reproduction in any medium, provided the original work is properly cited. 
targeting of $I L-10$ in DCs was carried out using siRNAs codelivered with adjuvant CpG (a TLR9 ligand) and a pDNAantigen (the idiotype protein of A20 B cell lymphoma) associated with a PLGA-PEI (poly[lactic-co-glycolic acid] and polyethylenimine)-derived microparticle [16]. This approach depends on the inclusion of cationic polymer (PEI) in the PLGA-based formulation to incorporate complexes of siRNAs, CpG, and DNA plasmid by electrostatic interaction, which potentially could be associated with apoptosis of APCs and reduction in the immune response $[17,18]$.

Stat 3 is a transcription factor member of the signal transducer and activator of transcription (Stat) protein family. Treatment of immune cells (particularly T cells) with interleukin-6 (IL-6), IL10 , hepatocyte growth factor, epidermal growth factor, as well as other growth factors and cytokines, promotes Stat 3 phosphorylation, and consequently Stat 3 translocation to the nucleus, where it binds specific DNA sequences and promotes gene expression [19]. Nuclear factor- $\kappa \mathrm{B}(\mathrm{NF}-\kappa \mathrm{B})$ is a key proteinprotein binding partner and transcriptional coregulator of Stat3, and has been linked to the expression of numerous oncogenic and inflammatory genes [20]. Research on nullizygous Stat $3^{-/-}$ immune cells has highlighted the role of Stat 3 in inhibiting certain functions of DCs. DCs from Stat ${ }^{-1-}$ knockout mice exhibited enhanced expression of MHC II, CD80, and CD86 and enhanced antigen crosspresentation [21]. Furthermore, DCs derived from Stat $3^{-/-}$knockout mice exhibited an improved activation of antigen-specific CD4 T cells ex vivo [22]. In contrast, the expression of Stat 3 by DCs in the tumor microenvironment inhibited initiation of the adaptive immune response, and led to an immunosuppressive phenotype [23].

In this study, we have investigated the feasibility of conjugating siRNAs to MIS416, using a disulfide linkage (MIS416SS-siRNA), with the primary objective of delivering functionally active siRNAs to the cytoplasm of APCs to modulate gene expression. We used Stat3 as a siRNA target [24-27], which showed that MIS416-SS-siRNA conjugates have the potential to deliver siRNAs to APCs, and that MIS-SSStat3_siRNA conjugates are able to inhibit Stat3 mRNA transcription in DCs cultured in vitro.

\section{Materials and Methods}

\section{Preparation of the MIS416-PE conjugate}

Biotinylation of MIS416. Pellets of MIS416 (10 mg) were washed in sodium bicarbonate $\left(\mathrm{NaHCO}_{3}\right)$ buffer $(50 \mathrm{mM}$, $\mathrm{pH}=8.35,1.5 \mathrm{~mL}$ ). Sulfo-NHS-biotin (Thermo Scientific) $(1.2 \mathrm{mg})$ was dissolved in $\mathrm{NaHCO}_{3}$ buffer $(50 \mathrm{mM}, \mathrm{pH} 8.35$, $1 \mathrm{~mL}$ ) and added to the washed pellet. The mixture was agitated overnight. The supernatant was removed after centrifugation $(5,000 \mathrm{~g}, 5 \mathrm{~min})$ and the pellet washed three times with phosphate-buffered saline (PBS) buffer $(1.5 \mathrm{~mL})$. The biotinylated microparticle $(1 \mathrm{mg})$ was suspended in PBS $(200 \mu \mathrm{L})$. An aliquot $(20 \mu \mathrm{L}, 4 \mu \mathrm{g})$ of streptavidin-PE stock solution (BioLegend) was added and the mixture agitated for $3 \mathrm{~h}$ at RT. The resulting pellet was washed in PBS $(1.5 \mathrm{~mL})$ twice and centrifuged $(5,000 \mathrm{~g}, 5 \mathrm{~min})$. After centrifugation and washing with PBS the pellet was resuspended in PBS $(200 \mu \mathrm{L})$.

\section{Preparation of the MIS416-biotin-Streptavidin-biotin-SS- STAT3-FAM (MIS416-SS-Stat3_siRNA) conjugates}

The complete conjugation procedure to couple biotinylated molecules to MIS416 has been published previously
[15]. Briefly, streptavidin (Invitrogen, $2.5 \mathrm{mg} / \mathrm{mL}$ in PBS) was used to conjugate MIS416-biotin particles and biotin-SSSTAT3-FAM (Integrated DNA technology, MW $14591 \mathrm{~g} / \mathrm{mol}$ ). Streptavidin $(50 \mu \mathrm{L}, 125 \mu \mathrm{g}, 2.37$ nmoles $)$ was added to biotin-SS-STAT3-FAM $(20 \mu \mathrm{L}, 69 \mu \mathrm{g}, 4.74$ nmoles $)$ in an Eppendorf tube to occupy two of the four biotin-binding sites of Streptavidin. The mixture was agitated for $4 \mathrm{~h}$ at $4^{\circ} \mathrm{C}$. MIS416-biotin $\left(0.4 \mathrm{mg}\right.$ in $200 \mu \mathrm{L}$ in $\mathrm{NaHCO}_{3}$ buffer, $\mathrm{pH}$ 8.3) was added to the mixture and agitated overnight at $4^{\circ} \mathrm{C}$. After centrifugation $(5,000 \mathrm{~g}, 5 \mathrm{~min})$ and washing with $\mathrm{PBS}$, the pellets were resuspended in PBS $(200 \mu \mathrm{L})$. The fluorescence of FAM (excitation $488 \mathrm{~nm}$, emission $520 \mathrm{~nm}$ ) was used to compare multiple preparations of MIS416-SS-STAT3_siRNA. As a negative control, MIS416-SS-control_siRNA (Integrated DNA technology, MW $13389 \mathrm{~g} / \mathrm{mol}$ ) was generated following the procedure just described. The Stat3-specific siRNA sequences were exactly as previously published, 5'-GGGUCU GGCUAGACAAUAUTT-3' (sense) and 5'-AUAUUGUCU AGCCAGACCCTT-3' (antisense) [27]. The scrambled control siRNA sequences were 5'-UUCUCCGAACGUGUCAC GUTT-3' (sense) and 5'-ACGUGACACGUUCGGAGAA TT-3' (antisense) [27].

\section{Internalization of the MIS416-PE conjugate in murine splenocytes}

Splenocytes were collected from C57BL/6 mouse spleens. Animal ethics approval was granted by the University of Otago Animal Ethics Committee, protocol numbers ET10/13 and AEC17/14. Cells were washed in PBS (300 $\mathrm{g}, 5 \mathrm{~min})$ and red blood cells were lysed with ammonium chloride buffer (4.15 $\mathrm{g} \mathrm{NH}_{4} \mathrm{Cl}, 0.5 \mathrm{~g} \mathrm{KHCO}_{3}, 0.0186 \mathrm{~g}$ EDTA, $500 \mathrm{~mL}$ milli$\mathrm{Q}$ water, $\mathrm{pH} 7.4$ ) for $3 \mathrm{~min}$ at $37^{\circ} \mathrm{C}$. MIS416-PE (1, 5 or $10 \mu \mathrm{g}$ ) was incubated for 1,4 , or $24 \mathrm{~h}$ with $2 \times 10^{6}$ splenocytes at $37^{\circ} \mathrm{C}$ in $2 \mathrm{~mL}$ of the medium. The same protocol was used at $4{ }^{\circ} \mathrm{C}$ to evaluate the attachment of MIS416-PE to the cell surface (negative control). After the uptake, splenocytes were washed with PBS (300 $\mathrm{g}, 5 \mathrm{~min})$ and stained with CD45R/ B220 (clone A3-6B2; BioLegend), CD11c (clone N418; BioLegend), F4/80 (clone BM8; BioLegend), LY6 g (RB68C5; BioLegend) and CD3 (clone 17A2; BioLegend) $\left(1 \mu \mathrm{g} / 10^{6}\right.$ cells for each antibody in $100 \mu \mathrm{L}$ of PBS for $15 \mathrm{~min}$ at $4^{\circ} \mathrm{C}$ ). FACS analysis: Cells positive for different markers, including CD45R (B cells), CD11c (DCs), F4/80 (Macrophages), Ly6 g (Neutrophils), CD3 (T cells) were subsequently gated on PE to assess specific internalization of the microparticle formulation (MIS416-PE) (Supplementary Fig. S1; Supplementary Data are available online at www.liebertpub .com/nat).

\section{Bone marrow-derived cell preparation}

Bone marrow was harvested from the femurs and tibias of C57BL/6 mice and red blood cells were lysed with $2 \mathrm{~mL}$ of ammonium chloride buffer $\left(4.15 \mathrm{~g} \mathrm{NH}_{4} \mathrm{Cl}, 0.5 \mathrm{~g} \mathrm{KHCO}_{3}\right.$, $0.0186 \mathrm{~g}$ EDTA, $500 \mathrm{~mL}$ milli-Q water, $\mathrm{pH} 7.4$ ) for $3 \mathrm{~min}$ at $37^{\circ} \mathrm{C}$. Bone marrow cells were then plated at $3 \times 10^{6}$ cells/ well in a six-well plate with $5 \mathrm{~mL}$ of complete medium [Iscove's modified Dulbecco's medium (IMDM) (Invitrogen) supplemented with 5\% fetal bovine serum (Moregate), and $5 \times 10^{-5} \mathrm{M}$ 2-mercaptoethanol (Gibco, Life Technologies)] and cultured for 6 days in the presence of $20 \mathrm{ng} \mathrm{mL}^{-1}$ recombinant GM-CSF ( ProSpec) in humidified incubators 
with $5 \% \mathrm{CO}_{2}$ at $37^{\circ} \mathrm{C}$. Every 3 days, half of the cell culture medium of the bone marrow-derived dendritic cell (BMDC) culture was replaced with fresh medium containing the above additives. BMDC was used at day 6 or day 7 when more than $80 \%$ of the cells were CD11 ${ }^{+}$.

\section{Cytokine ELISA assay following BMDC activation using MIS416-SS-siRNA conjugates}

After treatment with MIS416-SS-siRNA conjugates, the level of cytokines in the culture supernatants were measured using a standard sandwich ELISA assay. Briefly, 96well flat-bottomed ELISA plates were coated with $50 \mu \mathrm{L}$ of corresponding purified antibodies [IL-6, IL-10, TNF- $\alpha$ (BioLegend), IFN- $\gamma$ (ProSpec) $\left(2 \mu \mathrm{g} \mathrm{mL}{ }^{-1}\right.$; BD Pharmingen)], diluted in coating buffer overnight at $4^{\circ} \mathrm{C}$, then washed six times in washing buffer (PBS $+0.05 \%$ Tween 20). The plates were blocked with $200 \mu \mathrm{L}$ blocking buffer (PBS $+1 \%$ BSA) for $2 \mathrm{~h}$ at $37^{\circ} \mathrm{C}$, then washed six times in washing buffer. Recombinant cytokine standards (concentration of standards from 20 to $20 \mathrm{ng} \mathrm{mL}^{-1}$, IL-6, IL10, TNF- $\alpha$, and IFN- $\gamma$ ) and culture supernatants were diluted in blocking buffer, and $50 \mu \mathrm{L} /$ well was added to each duplicate well and then incubated for $2 \mathrm{~h}$ at $37^{\circ} \mathrm{C}$, followed by six washes. Biotinylated antibodies against these interleukins (BD Pharmingen) were diluted in blocking buffer $\left(1 \mu \mathrm{g} \mathrm{mL}^{-1}\right)$, and $100 \mu \mathrm{L} /$ well was added, then incubated for $1 \mathrm{~h}$ at $37^{\circ} \mathrm{C}$ and then washed six times. Streptavidin-HRP ( BioLegend) was diluted 1/3,000 in the blocking buffer, and $100 \mu \mathrm{L}$ was added to each well, then incubated at room temperature (RT) for $30 \mathrm{~min}$, followed by eight washes. TMB substrate (Life Technologies) was added $(100 \mu \mathrm{L} /$ well $)$, and incubated at RT for color development. Around $1 \mathrm{~N} \mathrm{H}_{2} \mathrm{SO}_{4}$ was added ( $100 \mu \mathrm{L} /$ well) to stop the reaction. The absorbance was then read by ELISA plate reader (BioTek synergy 2) at $450 \mathrm{~nm}$.

\section{In vitro $O T-1 T$ cell proliferation assay}

BMDCs at day 5 were plated $\left(5 \times 10^{5}\right.$ cells/well $)$ in 12 -well plates (1 mL of complete medium each well) and incubated with MIS416 $(0.5 \mu \mathrm{g})$ plus SIINFEKL $(0.5 \mu \mathrm{g})$, MIS416-SSsiStat3 $(0.5 \mu \mathrm{g})$ plus SIINFEKL $(0.5 \mu \mathrm{g})$, MIS416-SSsiControl $(0.5 \mu \mathrm{g})$ plus SIINFEKL $(0.5 \mu \mathrm{g})$, or untreated. After $24 \mathrm{~h}$ of incubation, cells were collected, washed in PBS $(300 \mathrm{~g}, 5 \mathrm{~min})$, and plated $\left(5 \times 10^{4}\right)$ in 24 -well plates $(0.5 \mathrm{~mL}$ of complete medium each well) and OT- 1 T cells $\left(5 \times 10^{5}\right.$ in $0.5 \mathrm{~mL}$ of medium) were added. OT-1 T cells were prepared as described previously [15], and were prestained with the VPD450 proliferative dye (BD Bioscience). Briefly OT-1 $\mathrm{T}$ cells were resuspended $\left(1 \times 10^{6} / \mathrm{mL}\right)$ in PBS and VPD450 was added to a final concentration of $1 \mathrm{mM}$. Cells were then incubated at $37^{\circ} \mathrm{C}$ for $10 \mathrm{~min}$ and washed three times in PBS ( $300 \mathrm{~g}, 5 \mathrm{~min}$ ) before adding them to DC cultures. After 48 or $72 \mathrm{~h}$ of incubation, cells were harvested and stained with infrared near IR-live/dead (Invitrogen, $0.05 \mu \mathrm{L}$ plus $100 \mu \mathrm{L}$ of PBS for $15 \mathrm{~min}$ at $4^{\circ} \mathrm{C}$ ). After washing in PBS, cells were stained in FACS buffer with CD8 (clone 53-6.7; Cell Lab, Beckman Coulter, Inc.) and CD69 (clone H1.2F3; Cell Lab) $\left(1 \mu \mathrm{g} / 10^{6}\right.$ cells of each antibody in $100 \mu \mathrm{L}$ of FACS buffer for $15 \mathrm{~min}$ at $4^{\circ} \mathrm{C}$ ). Samples were analyzed using a Gallios flow cytometer (Beckman Coulter, Inc.). In silico analysis was performed using FlowJo software (version 9; TreeStar, Inc.). The cells were gated for singlets (FSC-H vs. FSC-A), live/ dead, and $\mathrm{CD}^{+}$. The $\mathrm{CD} 8^{+}$gate was further analyzed using the proliferation software tool in FlowJo version 9 to calculate the percentage of proliferating $\mathrm{CD} 8^{+} \mathrm{OT}-1 \mathrm{~T}$ cells in each sample.

\section{Evaluation of Stat3 $m R N A$ levels}

BMDC, $5 \times 10^{5}$, at day 6 with $2 \mathrm{~mL}$ of complete IMDM (described in the cell culture section) were plated in a 12-well plate. MIS416-SS-STAT3_siRNA or MIS416-SS-BIM_siRNA $(3 \mu \mathrm{g})$, MIS416 $(3 \mu \mathrm{g})$, and MIS416-SS-control_siRNA $(3 \mu \mathrm{g})$ were added in separate wells, whereas one well with untreated cells was used as a control. MIS416 conjugates were incubated for 48 or $72 \mathrm{~h}$. RNA was extracted 48 or $72 \mathrm{~h}$ after siRNA treatment using the Ambion RNA Extraction Kit (Life Technologies) according to the manufacturer's instructions. RNA was quantified using a NanoDrop ND 1000 spectrophotometer. cDNA preparations were performed with the Superscript Vilo cDNA Synthesis Kit (Invitrogen) according to the manufacturer's instructions. Analysis by quantitative real-time PCR (Q-RT-PCR) of cDNA samples, was performed on a LightCycler 480 (Roche) using LightCycler 480 SYBR Green Master Mix assays (Roche) according to the manufacturer's instructions. The program used for the LightCycler480 was: start ( 1 cycle, 2 min $95^{\circ} \mathrm{C}$ ), amplification ( 40 cycles, $30 \mathrm{~s} 95^{\circ} \mathrm{C}, 1 \mathrm{~min} 60^{\circ} \mathrm{C}$ ), dissociation $\left(95^{\circ} \mathrm{C}\right.$ continuous). Bim, Stat3, B2 m, $\beta$-actin, Ywhaz, Rpl32, Minor, and IL1Orl cDNA levels (Supplementary Figs. S2 and S3) were quantified using Gapdh as the reference gene. Primer sequences are listed in Supplementary Table S1. The relative quantification was carried out using BioGazelle qBase+software.

\section{Evaluation of Stat3 protein levels}

BMDC, $2 \times 10^{6}$, at day 6 with $5 \mathrm{~mL}$ of complete IMDM (described in the BMDC preparation section) were plated in a 12-well plate. MIS416-SS-STAT3_siRNA or MIS416SS-BIM_siRNA $(3 \mu \mathrm{g})$, MIS416 $(3 \mu \mathrm{g})$, and MIS416-SScontrol_siRNA $(3 \mu \mathrm{g})$ were added in separate wells, whereas one well with untreated cells was used as a control. MIS416 conjugates were incubated for 48 or $72 \mathrm{~h}$. Proteins were extracted using RIPA buffer $[50 \mathrm{mM}$ Tris- $\mathrm{HCl}, \mathrm{pH} 7.4$, $150 \mathrm{mM}$ sodium chloride, $1 \mathrm{mM}$ ethylenediaminetetraacetic acid (EDTA), $1 \%$ NP-40, $1 \%$ sodium deoxycholic acid, $0.1 \%$ sodium dodecyl sulfate (SDS)] with the addition of complete protease inhibitor (cOmplete mini ${ }^{\mathrm{TM}}$; Roche), phenylmethylsulfonyl fluoride $1 \mathrm{mM}$ and $\mathrm{Na}$ Orthovanadate $1 \mathrm{mM}$. Western blots were performed on Bolt 4-12\% Bis-tris Plus acrylamide gels using Bolt Mes SDS running buffer. Electrophoresis was carried out for $40 \mathrm{~min}$ at $165 \mathrm{~V}$. Proteins were transferred using an iBlot ${ }^{\circledR}$ Gel Transfer Device according to the manufacturer's instructions. Nitrocellulose membranes were blocked with 5\% skim milk in PBST (PBS, 0.1\% TRITON) for $1 \mathrm{~h}$. Anti-beta Actin antibody diluted 1:10,000 (ab8227; ABCAM) and Stat3 (79D7) rabbit mAb diluted 1:2,000 (Cell Signaling Technology) were used to evaluate protein loading and to quantify Stat3 expression levels, respectively. Primary antibodies were detected with anti-rabbit HRP diluted 1:20,000 (A0545; Sigma) and ECL analysis was performed using Super Signal West Pico reagents according to the manufacturer's instructions. Kodak BioMax XAR Films were developed using a Protec ECOMAX X-Ray Film Processor. Developed films from western blots were analyzed using ImageJ software to quantify band density. The 
ratio between Stat 3 and $\beta$-Actin band density was used to define a relative density. A value of 1 has been arbitrarily attributed to cells treated with MIS416-SS-control_siRNA and has been used to compare relative density values of cells treated with MIS416 conjugates.
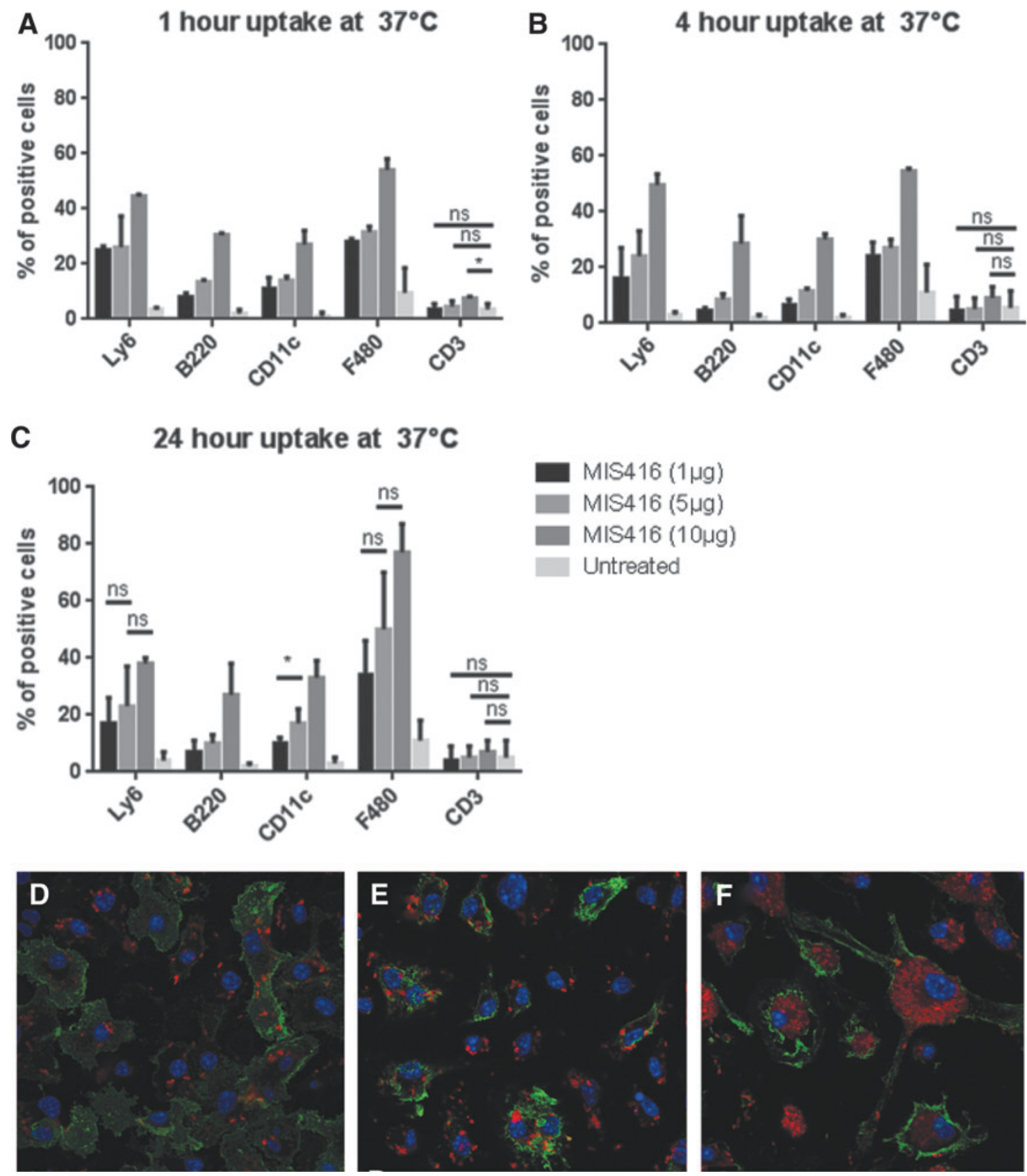

FIG. 1. Internalization of MIS416-PE (MIS416-biotin-streptavidin-PE) by splenocytes, and BMDCs. (A-C) Graphs showing internalization of MIS416-PE after 1,4 , or $24 \mathrm{~h}$, respectively, at $37^{\circ} \mathrm{C}$. Splenocytes were pulsed with MIS416-PE $(1,5$, or $10 \mu \mathrm{g})$ for 1,4 , or $24 \mathrm{~h}$. After incubation, cells were washed in PBS, and then immunocytochemically stained with five different antibodies in PBS (LY6, B220, CD11c, F480, CD3) to identify five different cell populations (neutrophils, B cells, DCs, macrophages, and T cells), respectively. The gating strategies are explained in Supplementary Fig. S1. Error bars represent standard error of the mean (SEM). ns, not significant; $* P<0.05$; $* * P<0.005$; $* * * P<0.0005$. The experiment was repeated three times. (D-F) Images showing BMDCs at 1, 4, and $24 \mathrm{~h}$, respectively, after internalization of MIS416-PE. BMDCs $\left(2 \times 10^{5}\right.$ on coverslips in $250 \mu \mathrm{L}$ of cell culture media) were treated with MIS416-PE $(3 \mu \mathrm{g})$ for 1,4 , and $24 \mathrm{~h}$. After incubation, cells were washed in PBS, and immunocytochemically stained with CD11c to identify DCs by incubating $1 \mu \mathrm{g} /$ $10^{6}$ cells in $100 \mu \mathrm{L}$ of PBS for $30 \mathrm{~min}$ at $4^{\circ} \mathrm{C}$. CD11c is shown in green, MIS416-PE in red, and DAPI (to stain nuclei) in blue. The images were taken using a Zeiss LSM 710 confocal microscope. BMDC, bone marrow-derived dendritic cell; PE, phycoerythrin. 
column graphs. Error bars represent the standard error of the mean (SEM).

\section{Results}

MIS416-PE conjugate is internalized by murine APC populations derived from splenocytes

MIS416 has been described as a microparticulate vector able to deliver attached cargo to DCs and other APCs [15]. To assess the targeting specificity of MIS416 in APCs, the uptake efficiency of MIS416 in various cell populations of the spleen was analyzed using flow cytometry. Murine splenocytes were pulsed with MIS416-Phycoerythrin (PE) conjugate (a fluorescent version of MIS416) for 1, 4, or $24 \mathrm{~h}$ at various concentrations, after which they were analyzed by flow cytometry. Different cell populations (macrophages, DCs, T cells, neutrophils, and B cells) were identified with specific antibodies (F480, CD11c, CD3, LY6, and B220), respectively. A $4{ }^{\circ} \mathrm{C}$ control was used to evaluate nonspecific binding of MIS416-PE to the cell surface.

Macrophages, DCs, neutrophils and B cells, but not T cells, internalized MIS416-PE (Fig. 1), with approximately $80 \%$ of the macrophages and approximately $40 \%$ of neutrophils, B cells, and DCs positive for MIS416-PE after $24 \mathrm{~h}$ of treatment at $37^{\circ} \mathrm{C}$. No major differences in internalization were observed from 1 to $4 \mathrm{~h}$ following treatment, indicating that most of the microparticle was internalized within the first hour in vitro at $37^{\circ} \mathrm{C}$. Robust MIS416-PE fluorescence was observed after $24 \mathrm{~h}$ of treatment with MIS416-PE. Internalization of MIS416-PE by macrophages increased by an additional $\sim 20 \%$ from 4 to $24 \mathrm{~h}$ of treatment, which was dependent on MIS416-PE concentration. Confocal microscopy using BMDCs additionally showed that MIS416-PE was readily internalized by BMDC after $1 \mathrm{~h}$ (Fig. 1D-F) and further MIS416-PE accumulation in the cytoplasm was observed at later time points. Increasing concentrations of MIS416-PE $(1,5,10 \mu \mathrm{g})$ directly correlated with increasing degrees of internalization in splenocytes. Experiments carried out at $4^{\circ} \mathrm{C}$, assuming either very little or no internalization at this temperature, showed that approximately $10 \%$ of the signal at $37^{\circ} \mathrm{C}$ was probably due to MIS416-PE binding to the surface of target cells as opposed to being internalized. Macrophages showed a higher signal at $4^{\circ} \mathrm{C}$ at all time points tested, suggesting they were more prone to cell surface binding effects at $4^{\circ} \mathrm{C}$ than other cell types.

\section{MIS416-SS-Stat3_siRNA downregulates Stat3 mRNA and protein levels in BMDCs}

We evaluated downregulation of Stat 3 mRNA and protein in vitro following 48 or $72 \mathrm{~h}$ of treatment of murine BMDCs with MIS416-SS-Stat3_siRNA conjugates, prepared according to our previously described method [15], compared with treatment with MIS416 alone or conjugated to control siRNA (MIS416-SS-control_siRNA). Analysis by Q-RTPCR revealed significant reduction of the Stat 3 mRNA levels to approximately $50 \%$ of the level of control treated cells, between DCs treated in vitro with MIS416-SS-Stat3_siRNA versus treatment of DCs with MIS416-SS-control_siRNA at $48(P<0.05)$ and $72 \mathrm{~h}(P<0.05)$ (Fig. 2).

Western blot studies were performed to evaluate Stat 3 protein levels after treatment of the murine BMDCs with MIS416,

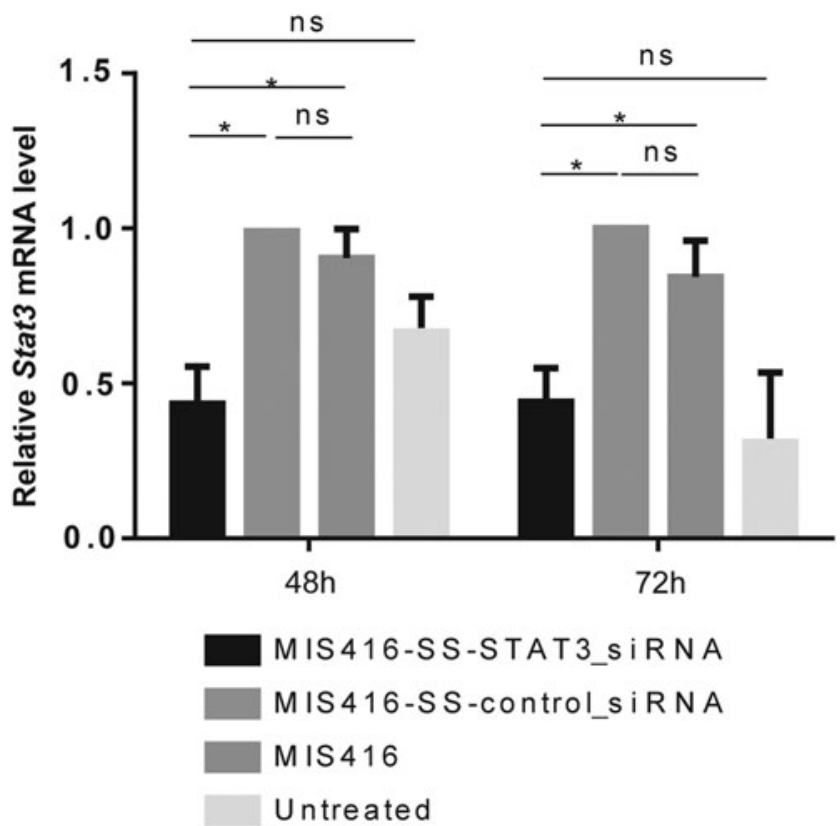

FIG. 2. Q-RT-PCR quantification of Stat3 mRNA levels. DCs were treated for 48 or $72 \mathrm{~h}$ with MIS416, MIS416-SSControl_siRNA, and MIS416-SS-Stat3_siRNA using previously published sequences for Stat3-targeting siRNAs [27]. Analysis by Q-RT-PCR was performed on cDNA generated from total RNA extracted from treated cells. Downregulation of Stat3 mRNA levels occurs at 48 and $72 \mathrm{~h}$ in all samples treated with MIS416-SS-Stat3_siRNA compared with controls. The relative level of expression of Stat 3 was set to 1 for MIS416-SS-Control_siRNA samples. The relative quantification was carried out using BioGazelle qBase+software. Error bars represent SEM. Results designated with ns were not significant. Results designated with * were significant $(P<0.05)$. This experiment was repeated three times.

MIS416-SS-Stat3_siRNA, or MIS416-SS-control_siRNA, and relative Stat 3 expression levels were quantified using $\beta$-actin for gel loading normalization. DCs treated with MIS416-SSStat3_siRNA expressed Stat3 protein at $48 \%$ of the level in MIS416-SS-control_siRNA-treated DCs at $48(P<0.05)$, and at $60 \%$ of the level of Stat3 protein in MIS416-SScontrol_siRNA-treated DCs at $72 \mathrm{~h}(P<0.05)$ (Fig. 3A, B).

\section{Immunomodulatory effects of MIS416-SS-siRNA conjugate treatment of BMDCs}

We next used ELISA assays to evaluate changes in the expression of cytokines, such as IFN- $\gamma$, IL-6, IL-10, and $\mathrm{TNF} \alpha$ in BMDCs following treatment with MIS416-SSsiRNA conjugates. Increased levels of IFN- $\gamma$ at $24 \mathrm{~h}$ were observed following treatment with MIS416-SS-Stat3_siRNA relative to MIS416-SS-control_siRNA conjugates (Fig. 3C). IL-6 and IL-10 levels were investigated at 6, 12, and $24 \mathrm{~h}$ following treatment of the BMDCs with MIS416-SSStat3_siRNA, MIS416-SS-control_siRNA, or MIS416 alone. The levels of IL-6 showed relatively little difference between the MIS416-SS-Stat3_siRNA and MIS416-SS-control_siRNA conjugate treatments, but IL-10 levels showed a significant increase at 6, 12, and $24 \mathrm{~h}$ with the MIS416-SS-Stat3_siRNA treatment relative to MIS416-SS-control_siRNA treatment (Fig. 3D and Supplementary Fig. S4A). There were no 
FIG. 3. Western blot quantification of Stat3 protein levels. (A) Graphs showing the relative Stat 3 protein levels following treatment of DCs for 48 or $72 \mathrm{~h}$ with MIS416, MIS416-SS-Control_siRNA, or MIS416-SSStat3_siRNA. Relative Stat3 protein levels were quantified using ImageJ software. (B) Shows an example of western blot of data used to quantify Stat3 protein levels in (A). The numbers above the gel lanes represent the relative protein level, which was determined from the band intensity using ImageJ software, and normalized relative to the MIS416-SS-control_siRNA-treated samples. (C) Graph of IFN- $\gamma$ cytokine levels following treatment of BMDCs for $24 \mathrm{~h}$ with MIS416, MIS416-SS-Stat3_siRNA, MIS416-SS-Control_siRNA, or no treatment. (D) Graph of ELISA assays of IL-6 cytokine levels in BMDCs at 6, 12, and $24 \mathrm{~h}$ following treatment with MIS416, MIS416-SSStat3_siRNA, MIS416-SS-control_siRNA, or no treatment. In all graphs, the error bars represent SEM, and the results designated with ns were not significant, whereas results designated with $*$ were significant $(P<0.05)$, or $* * \quad(P<0.005)$. These experiments were repeated three times.
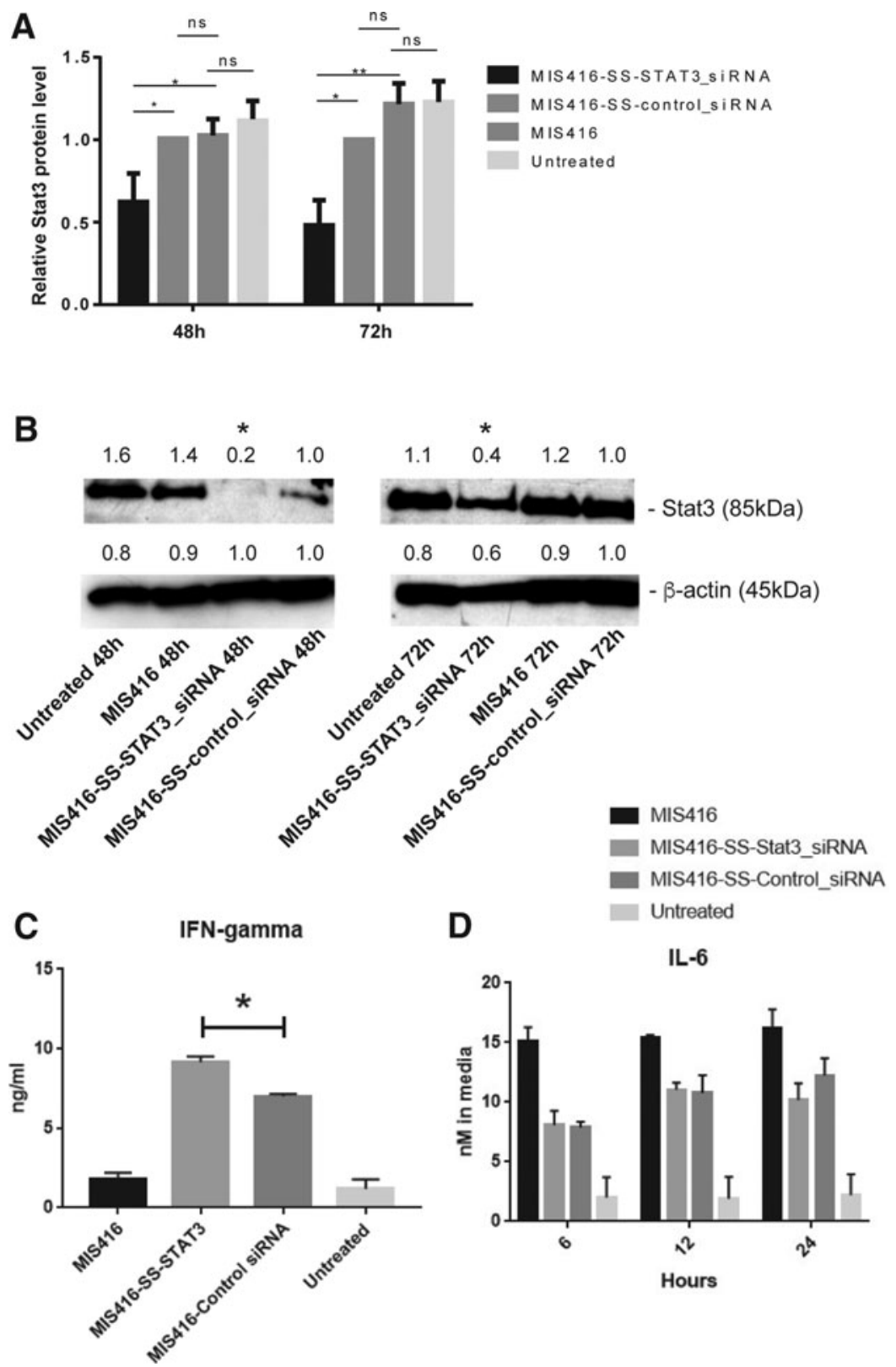

significant differences observed in $\mathrm{T}$ cell proliferation between MIS416-SS-Stat3_siRNA or MIS416-SS-control_siRNA conjugates, as determined in OT-1 T cell proliferation assays in the presence of SIINFEKL stimulation of T cells (Supplementary Fig. S4B). Lastly, a slight decrease in TNF $\alpha$ levels at 6 and $12 \mathrm{~h}$ was observed following treatment with MIS416-SSStat3_siRNA relative to MIS416-SS-control_siRNA conjugates (Supplementary Fig. S4C).

\section{Discussion}

In this study, we report the development of an MIS416-SSsiRNA conjugate to deliver functional siRNAs with the aim of achieving RNAi-mediated silencing and downregulation of gene expression in DCs. The MIS416-SS-siRNA microparticle conjugates successfully delivered functionally active siRNAs targeting Stat3 expression, resulting in downregulation of Stat3 mRNA and protein levels in DCs. Potential future applications of this technology could include MIS416-SSsiRNA-induced RNAi targeted to DCs to modulate DC function [16,29-31].

We chose Stat 3 as the siRNA target in the present study for the following reasons; (1) Stat3 was known to be involved in modulating immune responses [21-23]; (2) Stat3 was known to be expressed in the subpopulations of cells targeted by the MIS416 (ie, APCs) [10]; (3) in prior analysis of Stat3 mRNA and protein expression characteristics we identified that efficient siRNA-mediated knockdown of Stat3 in DCs was achievable; and (4) as determined before starting the siRNA experiments, treatment of APCs with MIS416 alone did not result in downregulation of Stat $3 \mathrm{mRNA}$ levels. With respect to the latter, we investigated the effect of MIS416 on the mRNA levels of four candidate genes (Minor, Bim, IL10R1, and Stat3) as possible targets for siRNAs in DCs $[32,33]$. The mRNA levels of the immune regulator $I L-10 R 1$ and the apoptosis regulators Bim and Minor were downregulated when DCs were 
treated with MIS416 (Supplementary Fig. S2), which is consistent with activation of a nonimmunosuppressive phenotype. However, the reduced mRNA levels caused by MIS416 would mask the effects of siRNAs on the mRNA level.

In contrast to the inhibitory effects of MIS416 on Bim and Minor mRNA levels, Stat3 mRNA levels were upregulated (Fig. 2), and Stat3 protein levels remained relatively unchanged after treatment with MIS416 (Fig. 3). Treatment of APCs with MIS416 has previously been found to induce IL-6 and IL-10 (Fig. 3, and see ref 23), which in turn stimulates increased Stat 3 mRNA levels and Stat 3 protein phosphorylation [34]. Therefore, while we have shown that MIS416SS-Stat3_siRNA conjugates inhibit Stat3 mRNA expression, the stimulatory effects of MIS416 on Stat3 expression and phosphorylation could potentially counteract this.

Nevertheless, we observed a significant increase in IFN- $\gamma$ levels, which is thought to result from the exposure in the cytoplasm of the cells to the Stat 3 and Control double-stranded siRNA sequences present in the conjugates. IL-10 levels also increased, but there was no change in IL-6 levels in BMDCs following the MIS-SS-Stat3_siRNA treatment. The observation of relatively low levels of TNF $\alpha$ cytokine activation, and the observation that there was relatively little difference in the OT-1 T cell proliferation assays between treatments, suggest that cell death was unlikely to be a major cause of the altered cytokine levels. Our findings that IL-10 levels were significantly increased by the MIS416-SS-Stat3_siRNA conjugate, and IL-6 levels were relatively unchanged compared with the MIS416-SS-control_siRNA, were very similar to the results observed in previous studies, where IL-10, but not IL-6 levels, was significantly increased in DCs in mice as a result of a Stat3 knockout mutation [35]. Our results are therefore consistent with the suggestion that the Stat 3 mRNA and protein levels in BMDCs were downregulated as a result of the silencing effect of the MIS416-SS-Stat3_siRNA conjugate.

In the present study, there were no differences in $\mathrm{T}$ cell proliferation between $\mathrm{T}$ cells treated with MIS416-SSStat3_siRNA plus SIINFEKL, compared with treatment with MIS416 (or MIS416-SS-control_siRNA) plus SIINFEKL in OT-1 T cell assays. We have previously investigated the immunomodulatory activity of MIS416 conjugates, which contained disulfide-linked SIINFEKL in vitro and in vivo [15]. In our previous in vivo investigations, we observed less immunostimulatory activity with a SIINFEKL conjugate linked to MIS416 with disulfide bond, than with a conjugate containing an irreversible, noncleavable bond [15]. These results suggested that the disulfide bond linking MIS416 and siRNA was probably not stable in extracellular tissues in vivo. Conjugates containing an alternative cleavable linkage between MIS416 and cargo, which are more stable than a disulfide bond in vivo, should therefore be sought for in in vivo applications. We have not investigated the stability of siRNAs conjugated to MIS416 (as MIS416-SS-Stat3_siRNA conjugates) in serum, or in vivo, due to the expected instability of the disulfide bond. In this regard, chemical modifications of the siRNAs, such as phosphorothioate, or boranophosphate, together with alternative cleavable linkages in the conjugate, would be helpful to improve the stability of MIS416-siRNA conjugates for in vivo applications.

Pradhan et al. targeted $I L-10$ in DCs using siRNAs codelivered with adjuvant CpG (a TLR9 ligand) plus pDNA antigen, encoding the idiotype protein of A20 B cell lymphoma, associated with PLGA-PEI-derived microparticles [16]. These microparticles were composed of the anti-IL10 siRNAs, which together with adjuvant and pDNA antigen, inhibited the production of IL-10 in DCs, and improved the survival of treated mice in an A20 B-lymphoma xenograft model. The delay in tumor growth in their experiments was found to result from the inclusion of the anti-IL1O siRNA in the conjugate. In another recent study, Zhang et al., linked adjuvant CpG to a Stat3targeting decoy oligodeoxynucleotide and achieved significant regression of acute myeloid leukemia in a murine model [36].

\section{Conclusions}

We describe, in this study, MIS416 conjugates with the aim of delivering functional siRNAs to APCs. MIS416-SSStat3_siRNA conjugates, which contained a Stat3 siRNA, inhibited Stat 3 mRNA, and protein expression in murine BMDCs treated in vitro without using transfection. These conjugates could therefore effectively deliver functional siRNAs to DCs in vitro, resulting in RNAi-mediated gene knockdown.

\section{Acknowledgments}

The authors thank Mr. Simon Pelham for assistance with DC preparations. This research was supported by a Cancer Society of New Zealand PhD Fellowship to FM, and funding from the Maurice Wilkins Center for Molecular Biodiscovery, and Otago Medical Research Foundation (OMRF).

\section{Author Disclosure Statement}

F.M., D.S.L., S.Y., and M.R.E. have no competing financial interests. G.A.W. is Chief Scientific Officer of Innate Immunotherapeutics Limited.

\section{References}

1. Palanca-Wessels MC, GC Booth, AJ Convertine, BB Lundy, GY Berguig, MF Press, PS Stayton and OW Press. (2016). Antibody targeting facilitates effective intratumoral siRNA nanoparticle delivery to HER2-overexpressing cancer cells. Oncotarget 7:9561-9575.

2. Gu S, Z Hu, W Ngamcherdtrakul, DJ Castro, J Morry, MM Reda, JW Gray and W Yantasee. (2016). Therapeutic siRNA for drug-resistant HER2-positive breast cancer. Oncotarget 7:14727-14741.

3. Mao M, J Chen, X Li and Z Wu. (2015). siRNA-TMEM98 inhibits the invasion and migration of lung cancer cells. Int J Clin Exp Pathol 8:15661-15669.

4. Maduri S. (2015). Applicability of RNA interference in cancer therapy: current status. Indian J Cancer 52:11-21.

5. Draghici B and MA Ilies. (2015). Synthetic nucleic acid delivery systems: present and perspectives. J Med Chem 58:4091-4130.

6. Brenner MK, S Gottschalk, AM Leen and JF Vera. (2013). Is cancer gene therapy an empty suit? Lancet Oncol 14:e447-e456.

7. Wittrup A and J Lieberman. (2015). Knocking down disease: a progress report on siRNA therapeutics. Nat Rev Genet 16:543-552.

8. Dominska M and DM Dykxhoorn. (2010). Breaking down the barriers: siRNA delivery and endosome escape. J Cell Sci 123(Pt 8):1183-1189.

9. Ma D. (2014). Enhancing endosomal escape for nanoparticle mediated siRNA delivery. Nanoscale 6:6415-6425.

10. Girvan RC, DA Knight, CJ O'loughlin, CM Hayman, IF Hermans and GA Webster. (2011). MIS416, a non-toxic microparticle adjuvant derived from Propionibacterium acnes comprising immunostimulatory muramyl dipeptide 
and bacterial DNA promotes cross-priming and Th1 immunity. Vaccine 29:545-557.

11. Boćko D, A Kosmaczewska, L Ciszak, R Teodorowska and I Frydecka. (2002). CD28 costimulatory molecule-expression, structure and function. Arch Immunol Ther Exp (Warsz) 50: 169-177.

12. Ferrand J and RL Ferrero. (2013). Recognition of extracellular bacteria by NLRs and its role in the development of adaptive immunity. Front Immunol 4:344.

13. He X, H Jia, Z Jing and D Liu. (2013). Recognition of pathogen-associated nucleic acids by endosomal nucleic acid-sensing toll-like receptors. Acta Biochim Biophys Sin Shanghai 45:241-258.

14. Khan ANH, N Kolomeyevskaya, KL Singel, MJ Grimm, KB Moysich, S Daudi, KS Grzankowski, S Lele, L Ylagan, et al. (2015). Targeting myeloid cells in the tumor microenvironment enhances vaccine efficacy in murine epithelial ovarian cancer. Oncotarget 6:11310-11326.

15. Mainini F, DS Larsen, GA Webster, SL Young and MR Eccles. (2015). Bridging small molecules to modified bacterial microparticles using a disulphide linkage: MIS416 as a cargo delivery system. PLoS One 10:e0145403.

16. Pradhan P, H Qin, D Leleux, IS Gwak, LW Kwak, K Roy, K Roy. (2014). The effect of combined IL10 siRNA and CpG ODN as pathogen-mimicking microparticles on Th1/Th2 cytokine balance in dendritic cells and protective immunity against B cell lymphoma. Biomaterials 35:5491-5504.

17. Khansarizadeh M, A Mokhtarzadeh, M Rashedinia, SM Taghdisi, P Lari, KH Abnous and M Ramezani. (2016). Identification of possible cytotoxicity mechanism of polyethylenimine by proteomics analysis. Hum Exp Toxicol 35:377-387.

18. Morimoto K, M Nishikawa, S Kawakami, SM Taghdisi, P Lari, KH Abnous, M Ramezani, M Hashida. (2003). Molecular weight-dependent gene transfection activity of unmodified and galactosylated polyethyleneimine on hepatoma cells and mouse liver. Mol Ther 7:254-261.

19. Song L, J Turkson, JG Karras, R Jove and EB Haura. (2003). Activation of Stat3 by receptor tyrosine kinases and cytokines regulates survival in human non-small cell carcinoma cells. Oncogene 22:4150-4165.

20. Yu H, M Kortylewski and D Pardoll. (2007). Crosstalk between cancer and immune cells: role of STAT3 in the tumour microenvironment. Nat Rev Immunol 7:41-51.

21. Kortylewski M, M Kujawski, T Wang, S Wei, S Zhang, S Pilon-Thomas, G Niu, H Kay, J Mulé, et al. (2005). Inhibiting Stat3 signaling in the hematopoietic system elicits multicomponent antitumor immunity. Nat Med 11:1314-1321.

22. Wang T, G Niu, M Kortylewski, L Burdelya, K Shain, S Zhang, R Bhattacharya, D Gabrilovich, R Heller, et al. (2004). Regulation of the innate and adaptive immune responses by Stat-3 signaling in tumor cells. Nat Med 10:48-54.

23. Rébé C, F Végran, H Berger and F Ghiringhelli. (2013). STAT3 activation: a key factor in tumor immunoescape. JAK-STAT 2:e23010.

24. Sanseverino I, C Purificato, B Varano, L Conti, S Gessani and MC Gauzzi. (2014). STAT3-silenced human dendritic cells have an enhanced ability to prime IFN $\gamma$ production by both $\alpha \beta$ and $\gamma \delta$ T lymphocytes. Immunobiology 219:503-511.

25. Melillo JA, L Song, G Bhagat, AB Blazquez, CR Plumlee, C Lee, C Berin, B Reizis and C Schindler. (2010). Dendritic cell (DC)-specific targeting reveals Stat3 as a negative regulator of DC function. J Immunol 184:2638-2645.

26. Nefedova Y, M Huang, S Kusmartsev, R Bhattacharya, P Cheng, R Salup, R Jove and D Gabrilovich. (2004).
Hyperactivation of STAT3 is involved in abnormal differentiation of dendritic cells in cancer. J Immunol 172:464-474.

27. Alshamsan A, A Haddadi, S Hamdy, J Samuel, AO El-Kadi, H Uludağ and A Lavasanifar. (2010). STAT3 silencing in dendritic cells by siRNA polyplexes encapsulated in PLGA nanoparticles for the modulation of anticancer immune response. Mol Pharm 7:1643-1654.

28. Chen Q, H Wang, Y Liu, Y Song, L Lai, Q Han, X Cao and $Q$ Wang. (2012). Inducible microRNA-223 down-regulation promotes TLR-triggered IL-6 and IL-1 $\beta$ production in macrophages by targeting STAT3. PLoS One 7:e42971.

29. Jadidi-Niaragh F, F Atyabi, A Rastegari, N Kheshtchin, S Arab, H Hassannia, M Ajami, Z Mirsanei, S Habibi, et al. (2017). CD73 specific siRNA loaded chitosan lactate nanoparticles potentiate the antitumor effect of a dendritic cell vaccine in 4T1 breast cancer bearing mice. J Control Release 246:46-59.

30. Dong Z, Y Chen, Y Peng, F Wang, Z Yang, G Huang, Y Chen, Z Yuan, T Cao and Y Peng. (2017). Concurrent CCR7 overexpression and RelB knockdown in immature dendritic cells induces immune tolerance and improves skin-graft survival in a murine model. Cell Physiol Biochem 42:455-468.

31. Ke N, A Su, W Huang, P Szatmary and Z Zhang. (2016). Regulating the expression of CD80/CD86 on dendritic cells to induce immune tolerance after xeno-islet transplantation. Immunobiology 221:803-812.

32. Ahn Y-H, S-O Hong, JH Kim, KH Noh, KH Song, YH Lee, JH Jeon, DW Kim, JH Seo and TW Kim. (2015). The siRNA cocktail targeting interleukin 10 receptor and transforming growth factor- $\beta$ receptor on dendritic cells potentiates tumour antigen-specific CD8(+) T cell immunity. Clin Exp Immunol 181:164-178.

33. Wang T, Q Jiang, C Chan, KS Gorski, E McCadden, D Kardian, D Pardoll and KA Whartenby. (2009). Inhibition of activationinduced death of dendritic cells and enhancement of vaccine efficacy via blockade of MINOR. Blood 113:2906-2913.

34. Iwata-Kajihara T, H Sumimoto, N Kawamura, R Ueda, T Takahashi, H Mizuguchi, M Miyagishi, K Takeda and Y Kawakami. (2011). Enhanced cancer immunotherapy using STAT3-depleted dendritic cells with high Th1-inducing ability and resistance to cancer cell-derived inhibitory factors. J Immunol 187:27-36.

35. Assi H, J Espinosa, S Surprise, M Sofroniew, R Doherty, D Zamler, PR Lowenstein and MG Castro. (2014). Assessing the role of STAT3 in DC differentiation and autologous DC immunotherapy in mouse models of GBM. PLoS One 9:e96318.

36. Zhang Q, DMS Hossain, P Duttagupta, D Moreira, X Zhao, H Won, R Buettner, S Nechaev, M Majka, et al. (2016). Serum-resistant CpG-STAT3 decoy for targeting survival and immune checkpoint signaling in acute myeloid leukemia. Blood 127:1687-1700.

Address correspondence to: Michael R. Eccles, PhD Department of Pathology University of Otago 56 Hanover Street, 9016 Dunedin 9054 New Zealand

E-mail: michael.eccles@otago.ac.nz

Received for publication September 3, 2017; accepted after revision March 20, 2018. 